\section{La Biblioteca James Lind}

La Biblioteca del Real Colegio de Médicos de Edimburgo, que fue fundada en 1682 por Sir Robert Sibbald (1641-1742), ha llegado a convertirse en una de las colecciones de escritos médicos de valor histórico más importantes del mundo. A mediados de los años noventa del siglo pasado se concibió la idea de crear una biblioteca en línea para dar a conocer algunas de las obras de la colección. Fue así como en 1998, exactamente 50 años después de publicado el ensayo clínico aleatorizado en que se puso a prueba la estreptomicina para el tratamiento de la tuberculosis, el Colegio lanzó un sitio conocido por Controlled trials from history [Los ensayos controlados en la historia]. Al cabo de un tiempo el sitio se rediseñó, se enriqueció con ensayos explicativos y más archivos históricos, y se lanzó de nuevo en la Biblioteca James Lind durante la celebración del $250^{\circ}$ aniversario de haberse publicado el tratado de Lind sobre el escorbuto [Treatise of the scurvy]. Con ello se ha puesto al alcance del público y de los profesionales una fuente de información que les permite mejorar sus conocimientos acerca de las pruebas imparciales para la investigación de los tratamientos administrados en el contexto de la atención de salud.

La función explicativa e ilustrativa de la Biblioteca James Lind. Aunque algunos tratamientos tienen un efecto tan evidente que no hace falta someterlos a pruebas suplementarias, en la mayor parte de los casos el efecto es más sutil o incluso producto del azar. Como resultado, un tratamiento ineficaz o nocivo puede pasar por eficaz, mientras que uno bueno puede parecer inútil. De ahí que sea tan importante contar con pruebas imparciales y educar al público acerca de ellas para que aprenda a separar la información fidedigna de la que no lo es.

En su interés por defender los intereses del público, actualmente diversas entidades que basan sus decisiones en las pruebas científicas en torno a los efectos deseables e indeseables de los tratamientos médicos exigen que las pruebas se generen mediante métodos imparciales. Sin embargo, el público sabe muy poco acerca de las características de estas pruebas, y subsanar esta falta de información es precisamente la finalidad de la Biblioteca James Lind, que busca demostrar mediante una serie de ensayos cortos que los fundamentos teóricos de las pruebas imparciales no son nuevos, sino por lo menos centenarios. Los ensayos también explican por qué es necesario realizar las pruebas de un modo imparcial y comparar distintos tratamientos; cómo se evitan los sesgos; cómo se descubren los efectos imprevistos de algunos tratamientos; cómo se interpretan los resultados de estudios comparativos realizados imparcialmente; y por qué es importante, a la hora de evaluar los resultados de un tratamiento, llevar a cabo revisiones sistemáticas de todas las pruebas existentes en un momento dado. Gracias a las traducciones realizadas por la Organización Mundial de la Salud y sus oficinas regionales, los ensayos pueden consultarse sin costo alguno no solo en inglés, sino también en árabe, chino, francés, portugués, ruso y español. El contenido de los ensayos está tomado de centenares de manuscritos, libros, artículos y otras fuentes. La Biblioteca cuenta, además, con un libro de 100 páginas titulado en inglés Testing treatments: better research for better healthcare [Cómo se prueban los tratamientos: una mejor investigación para una mejor atención de salud], del cual se han publicado o están por publicarse traducciones al árabe, chino, alemán, italiano, japonés y español. El acceso a la obra en inglés, árabe, chino y español es gratuito.

Un recorrido por Internet desde la antigüedad hasta el presente. Los materiales explicativos de la Biblioteca James Lind se nutren de fuentes que forman parte de la colección nuclear de la institución anfitriona, siendo dicha colección un archivo de Internet rastreable con centenares de documentos de contenido metodológico que recorren desde la antigüedad hasta el presente. Estos materiales pueden buscarse por texto, o bien por los conceptos metodológicos que ilustran. También figuran ordenados cronológicamente, por el apellido del autor en orden alfabético, y por el país de procedencia del autor. La Biblioteca contiene una gran cantidad de materiales vinculados con estos archivos, entre ellos comentarios, biografías, retratos y otras imágenes, algunos en formatos audiovisuales.

El archivo más antiguo, que es un papiro con jeroglíficos de alrededor de 1550 a.c. donde se describe cómo reducir una mandíbula dislocada, sirve para ilustrar un tratamiento que tuvo un efecto extraordinario deseado. Asimismo, un escrito sobre la talidomida ejemplifica un efecto adverso extraordinario pero indeseado. Un análisis de los estudios que se realizaron a raíz de la introducción de las sulfonamidas en los años treinta del siglo XX pone de relieve que algunos tratamientos tienen extraordinaria eficacia en el caso de ciertas enfermedades pero no en otras, prueba fehaciente de la necesidad de estudios con testigos efectuados con rigor. Que esta necesidad existe en el caso de efectos más sutiles se ha reconocido desde el siglo XX. No obstante, las primeras comparaciones cuantitativas con una justificación formal que se documentan en la Biblioteca James Lind datan de la primera mitad del siglo XVIII y guardan relación con los efectos de la inoculación contra la viruela y la eficacia relativa de distintas técnicas quirúrgicas para las litotomías y amputaciones. 
A partir de mediados del siglo XVIII aparecen las primeras evaluaciones cuantitativas de los tratamientos, algunas del propio Lind. En la Biblioteca también se documentan los primeros usos del vocablo "placebo" en su sentido actual, además de los primeros casos del uso de placebo y de la administración de los tratamientos a ciegas.

El uso de grupos de testigos tratados sin parcialidad para resolver diferencias de opinión en torno a las virtudes de distintos tratamientos se remontan al siglo XIX, época en que Jules Gavarret ya insistía en la necesidad de estudiar a un grupo suficientemente grande de pacientes. Los documentos que alberga la Biblioteca James Lind demuestran claramente el paulatino incremento entre los siglos XIX y XX de la aplicación y valoración de los conceptos en que se fundamentan las pruebas imparciales, los cuales se vienen aplicando más ampliamente desde la segunda mitad del siglo XX. Hay obras en la Biblioteca donde se documentan los principios metodológicos subyacentes de ese tipo de pruebas, hasta el momento en que su aplicación generalizada empezó a reflejarse en los libros de texto. En los años sesenta del pasado siglo muchos ya reconocían la importancia de los grupos testigo, obtenidos por alternación o por aleatorización, y sabían que los grupos comparados debían tener características similares. También se conocían ya los posibles sesgos vinculados con el patrocinio de los estudios por empresas comerciales.

Debido a que los aspectos teóricos de las pruebas imparciales a las que se someten los tratamientos cambian continuamente, la Biblioteca James Lind se esfuerza por actualizarse mediante la recolección de materiales procedentes del mundo entero. De hecho, agradece el envío de sugerencias a la dirección feedback@jameslind library.org

El enriquecimiento de la historia de la medicina. El grupo editorial de la Biblioteca cuenta con un historiador de la medicina que, junto con muchos otros especialistas en ese campo, ha escrito sobre la materia y hecho aportaciones muy valiosas a la colección de la Biblioteca. Ésta a su vez ha enriquecido la historia de la medicina dando a conocer ejemplos de la aplicación de enfoques metodológicos poco conocidos previamente, especialmente en idiomas distintos del inglés. Se desprende de estos materiales que los ensayos clínicos aleatorizados no los inventaron solamente los ingleses, puesto que los informes al respecto que datan de los años veinte del siglo pasado provienen no solo de Inglaterra, sino también de Alemania, Dinamarca, Estados Unidos y Francia. En algunos casos se trata de trabajos que escasamente se han documentado en otras historias de la medicina. Los materiales posteriores a 1940 han permitido obtener y publicar varios informes escritos por personas que participaron en algunos estudios pioneros, como los de Guy Scadding sobre las sulfonamidas.

La Biblioteca en lo sucesivo. La Biblioteca James Lind ha tenido una gran acogida. Ha recibido varios galardones, entre ellos el premio SCI/Tech que le otorgó Scientific American en 2003. Desde su creación, la Biblioteca ha sido reseñada en los medios de comunicación públicos, en el sitio web de la British Broadcasting Corporation (BBC), que es la cadena televisiva más importante de Gran Bretaña, y en publicaciones académicas tales como The Lancet, Hospital Doctor y Controlled Clinical Trials.

Personas del mundo entero consultan la Biblioteca James Lind. De ellas, más de la mitad radican en Europa, una tercera parte en el continente americano y el resto en otras partes del mundo. La traducción de algunos materiales a otros idiomas seguramente redundará en un aumento del número de visitantes al sitio web.

De los elementos que contiene la Biblioteca, los ensayos explicativos y la obra Testing Treatments son los más populares. Al respaldo de Scientific American se suma el de entidades como la Organización Panamericana de la Salud (OPS) y la Colaboración de Ensayos Clínicos del Reino Unido [UK Clinical Research Collaboration]. Debido a la extraordinaria calidad de los materiales que contiene la Biblioteca y al enorme interés que han suscitado, revistas de prestigio, como Journal of the Royal College of Physicians of Edinburgh $\mathrm{y}$ The Journal of the Royal Society of Medicine, publican con regularidad artículos comisionados originalmente para la Biblioteca.

En los próximos años se creará una sección nueva para dar a conocer la evolución de los métodos y conceptos propios de la investigación epidemiológica. Se agregarán los trabajos originales que describen los hitos producidos a lo largo del camino, junto con comentarios acerca de ellos. (The James Lind Library Editorial Team. The James Lind Library: explaining and illustrating the evolution of fair tests of medical treatments. J R Coll Physicians Edinb 2008; 38:259-64. Disponible en: http:/ / www.jameslindlibrary.org/pdf/ jll-article.pdf. Acceso el 23 de septiembre de 2008). 